\title{
Tabasco: Entre el Agua y el Desastre
}

\author{
Dr. Ángel Bautista García
}

Un grupo de investigadores coordinados por Leticia Romero Rodríguez, doctora en Ciencias Sociales y profesora en la Universidad Juárez Autónoma de Tabasco, nos presentan un panorama que quizá muchos no conocemos respecto del fenómeno de la inundación, y que afectó a muchos tabasqueños en sus personas y propiedades. Se trata de la "gran inundación" de 2007, que incluso provocó la muerte de familiares y conocidos, y en donde se registraron daños en más del $70 \%$ del territorio estatal. Hasta hoy no ha sido posible clasificar esta catástrofe entre "naturales" o "provocadas".

En la primera parte de la obra titulada "El ayer de las inundaciones", están algunos datos y testimonios de este fenómeno que ha sido recurrente en Tabasco, y del que la historia nos da cuenta, aunque no siempre con la veracidad que el caso requiere.

Es por demás interesante conocer la historia de las inundaciones en Tabasco, porque a través de éstas podemos imaginar cómo la gente que vivió en las primeras décadas del siglo XX hasta los años cincuenta, este fenómeno no significaba exactamente una tragedia 0 una contingencia. Era lo contrario: lo vivían como algo natural e incluso lo esperaban.

Aquellos tiempos en que las condiciones atmosféricas eran estables, las personas que en su mayoría se dedicaban a la agricultura, sabían con suficiente exactitud en qué momento comenzaba la época de lluvias, la época de seca o estiaje; se guiaban por la experiencia y en algunos casos por las fases de la luna para la siembra exitosa del maíz, del frijol, y de todas las especias que se cultivaban en sus campos; además de la procreación y crianza de los animales de traspatio.

En la segunda parte titulada "Entre el agua y el desastre" se hallan elementos concretos referentes al trabajo de investigación realizado entre algunas personas de comunidades afectadas por el fenómeno pluvial y fluvial de 2007.

En esta sección, los autores nos presentan las experiencias vividas, narradas con algunos detalles que la mayoría de los habitantes de las comunidades afectadas experimentó durante la contingencia.
Entre el agua y el desastre trae a la memoria acontecimientos que para muchos tabasqueños representa una confrontación histórica y fenomenológica en virtud de lo siguiente:

Existe información que proporcionan las personas de edad avanzada en el municipio de Nacajuca, de cuando esta población era considerada una villa, con pocos habitantes pero atravesada por el río Nacaxuxuca. Estos datos fueron recopilados entre los habitantes de la hoy ciudad de Nacajuca.

Dicen que la mayoría de los jefes de familia tenían la experiencia año con año de esperar la época de la "creciente"; para cuando ésta llegaba construían un "tapanco" (entarimado) a base de madera, un lugar para guardar provisiones suficientes para el tiempo que durara la inundación.

Ubicamos esta información en el tiempo y nos remontamos a mediados del siglo pasado cuando la mayoría de los jefes de familia se dedicaban a la agricultura, que era el medio natural de subsistir y de alimentarse, aunque también se practicaba la ganadería y el comercio en menor escala.

Pero a diferencia de lo que sucede actualmente, en aquel tiempo, las instituciones de gobierno muy poco aportaban a las personas cuyas casas quedaban entre el agua de la creciente del río -por no decir que, nada- tal vez porque esto se consideraba un acontecimiento natural.

Es más, no era considerado como catástrofe 0 desastre natural, como se dice ahora. Entonces como escribiera el poeta paraiseño en su obra "En Tabasco"...En Tabasco, si el cielo destruye las cosechas, abre el río su caudal de peces y de conchas y se aleja frustrada la miseria.... Además el mismo poeta más adelante dice.... Yooo....Yooo prefiero a Tabasco, porque si he de morir alguna vez prefiero sea ahogado y no de sed....

Mientras duraba la creciente, el cayuco era el medio de transporte para ir de un sitio a otro, fuese para comprar o intercambiar algún producto necesario para la subsistencia familiar y los niños -quienes por la misma situación, desde sus primeros años, aprendían a nadar- se divertían mucho entre el agua, inventando juegos apropiados al ambiente y además 
Perspectivas Docentes 63

Tabasco: Entre el Agua y el Desastre

Dr. Ángel Bautista García

de asear sus cuerpos, porque entonces, el agua era limpia y servía incluso para ser consumida por los seres humanos, sin mayores problemas.

De esto último se encargaban las madres de familia, hirviendo el agua y de ese modo convertirla en potable, para beber y para elaborar los alimentos.

Poco a poco se miraba cómo cada día el nivel del agua descendía y surgían nuevamente el entorno original en cada una de las casas y propiedades, hasta llegar el río a su nivel y seguir viviendo, primero entre el lodo que quedaba y que día a día el sol se encargaba de ir endureciendo hasta quedar los caminos, los patios y algunas casas que no contaban con piso de cemento, en su estado seco y natural.

Los agricultores tornaban a sus campos aprovechando la humedad del suelo para lograr una nueva cosecha.

Jamás hubo noticias de daños; estos antepasados vivieron la cultura del agua, y la convivencia con ella era de tal modo que se aprovechaba, lo mismo la época de seca, como de inundación. Entonces sí se convivía con la naturaleza, sin considerarla un desastre y mucho menos que sucediese alguna desgracia entre la población.

Sin duda fueron otros tiempos, la verdad es que en las últimas décadas han aparecido en nuestro territorio una cantidad considerable de familias migrantes de otros entidades, mismas que han decido establecerse en Tabasco, desconociendo la orografía propia de estas tierras y edificando en sitios inconvenientes para la vida humana.

Estos y otros elementos de carácter administrativo gubernamental han sido en gran parte la causa de lo que ahora se considera un desastre -refiriéndonos a las inundaciones- ya que como hemos referido anteriormente, en el principio no fue así.

Los diversos apartados de este libro ilustran ampliamente la situación que muchos tabasqueños y avecindados vivieron en el 2007, dejando testimonio real de las consecuencias que hubo que afrontar en aquella ocasión.

Es una obra muy valiosa considerando la metodología empleada y los resultados obtenidos mediante la contrastación teórico-empírica, de la cual se obtuvieron datos por demás interesantes y que podrían ser útiles para toda la sociedad, sobre todo para quienes viven en zonas de riesgo y también para las autoridades responsables de salvaguardar la vida y patrimonio de quienes habitamos en Tabasco.

\section{SEMBLANZA DE AUTOR:}

Profesor investigador de la División Académica de Informática y Sistemas en la Universidad Juárez Autónoma de Tabasco.

miguel6792@hotmail.com

\section{REFERENCIA BIBLIOGRÁFICA:}

Romero, Leticia del C. (Coord.). (2011). Tabasco: entre el agua y el desastre. Tabasco, México: Editorial Clave y UJAT 